\title{
Development of Design Software for Plain Masonry Buildings
}

\author{
R. Marques ${ }^{1}$, J.P. Gouveia ${ }^{1}$, P.B. Lourenço ${ }^{1}$ and C. Leão ${ }^{2}$ \\ ${ }^{1}$ Institute for Sustainability and Innovation in Structural Engineering \\ Department of Civil Engineering, University of Minho, Portugal \\ ${ }^{2}$ Flagsoft Lda., Vila Nova de Gaia, Portugal
}

\begin{abstract}
As result of a benchmarking process on foreign computer codes for design of masonry buildings, the guidelines for the development of a Portuguese design software for plain masonry buildings are presented. The related software was inspired on Italian methods, particularly the RAN, and allows to perform a global response analysis of buildings, based on the assumption of a cumulative response of storeys and walls. Besides the assumptions of behaviour and equilibrium, modelling of stiffness and collapse mechanisms, the main features of the formulation adopted are presented. As a form of validation a case study is presented.
\end{abstract}

Keywords: plain masonry, design, software benchmarking, software development, case study.

\section{Introduction}

Masonry is an ancient construction typology of buildings, traditionally designed with non-engineered criteria or basic rules, as the example of the slope rule for pyramid faces in ancient Egypt. Furthermore, historical constructions constructed until the $20^{\text {th }}$ century were often prepared by builders with limited structural instruction. As a consequence, most of these constructions collapsed when subjected to exceptional loading events, as earthquakes.

On the other hand, the development of reinforced concrete and its large potential for construction to meet modern requirements, led to technological development of resources oriented to construction with this typology. In this scenario, masonry appears as a secondary option even for small buildings, and even if its economical and environmental advantages are often recognized.

In the case of Portugal, the low quality of masonry materials in the recent past and the threat of earthquakes conduced to generalized use of reinforced concrete structures. However, the functional and mechanical properties of brick/block 
systems currently in the Portuguese market, allow the use of masonry as a modern and seismic-resistant structural solution.

The traditional idea of weakness of masonry buildings in the presence of earthquakes is denied from a study [1] that demonstrate the possibility of building with unreinforced masonry up to three storeys in almost all the Portugal. This study was based on Italian commercial software for design, as no Portuguese software exists. The adopted software, based on macro-elements and capacity design, allows exploring the reserve of non-linear strength of structures in terms of displacement.

\section{State-of-the art for structural masonry software}

In Portugal, the structural design of buildings is essentially made using commercial software for the design of reinforced concrete structures. The few Portuguese engineers that have interest in designing with masonry, due to the lack of specific tools, are obliged to use hand calculations or customised spreadsheets.

On the other hand, the loss of masonry as a structural material caused the stagnation of knowledge and lack of guidance on the behaviour of these structures. In fact, the methodologies often used for design are based in a simple analysis of wall-to-wall element, which is even surpassed by methods introduced in Italy at 1980, as the seismic storey mechanism POR method [2].

Despite the oldness of the POR method and the sophistication of recent tools based on the finite element method (FEM), the basic POR assumptions were the seed for the development of Italian methods, based on modelling by macroelements.

\subsection{Software based on modelling by macro-elements}

Since the 1980s, distinct Italian macro-element methods for seismic analysis of masonry buildings were developed, as PEFV [3] and MAS3D [4] bi-dimensional methods, and 3Muri [5] and SAM [6] three-dimensional methods (Figure 1). Initially these methods only had an impact in the scientific community and the POR derivatives persisted as the method used by most Italian designers until the beginning of the $21^{\text {st }}$ century. This scenario changed only as consequence of the 2002 Molise earthquake, which leads to the introduction of the new Italian code OPCM 3274/2003 and its revision OPCM 3431/2005 [7].

The new Italian codes are aligned with the philosophy of the seismic European code EC8 [8], but collect additional aspects provided by the research and experience of effective application of the new rules of design in Italy. However, the application of OPCM at beginning caused constraints to designers, because the analysis methods and verification criterions introduced are excessively complex and they are not normally available to the designer. To solve this problem, several protocols were established between scientific and industrial partners to promote design and construction with masonry, namely by developing computation tools for designers. 

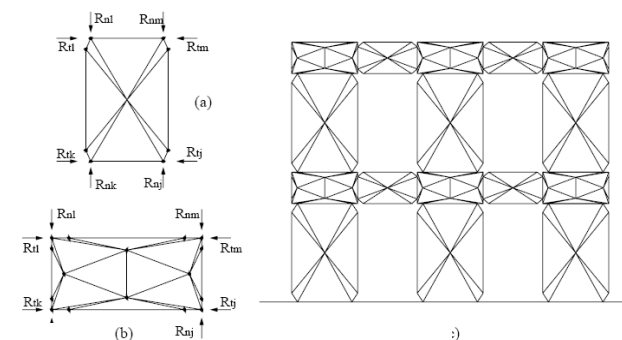

(a)
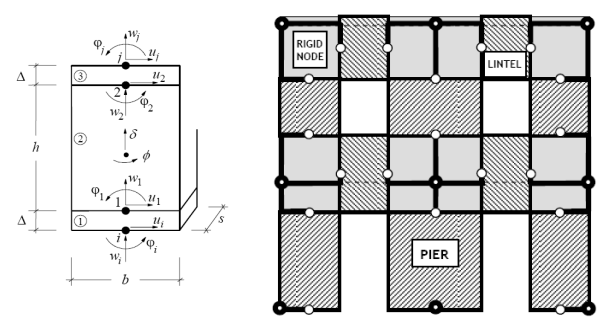

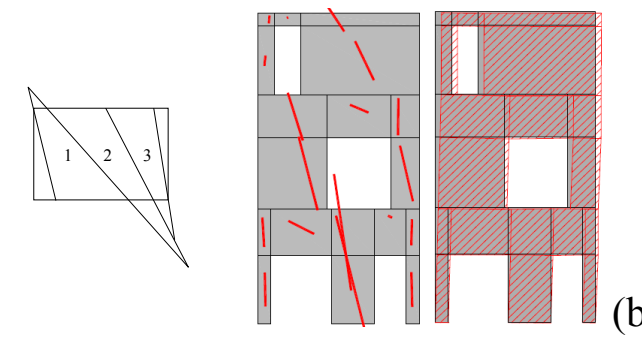

(b)

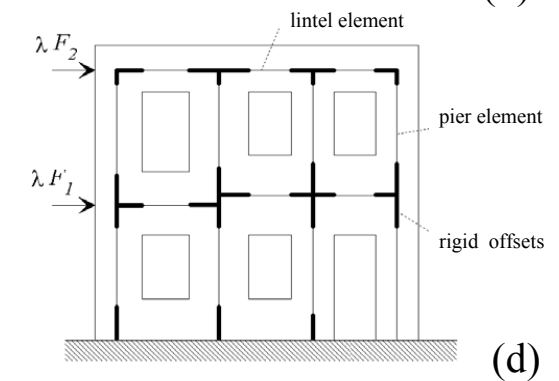

Figure 1: Modelling of walls trough macro-elements by methods: (a) PEFV [3]; (b) MAS3D [4]; (c) 3Muri [5]; (d) SAM [6].

As a consequence of the above, in last years several commercial computer codes have been developed, which can be identified in reference [9]. In particular, two new generation Italian programs are popular with to designers, the 3Muri [www.stadata.com] and ANDILWall/SAM II [www.crsoft.it/andilwall], which incorporate the macro-elements proposed by references [5] and [6], respectively.

While the 3Muri formulation is based on the kinematic equilibrium of the coupled macro-elements according to the established degrees of freedom, the SAM II creates an equivalent frame idealization for a global analysis. In addition to 3Muri and SAM II, the RAN $[10,11]$ is another promising Italian macro-element method. The RAN allows a linear static seismic analysis at each storey, and a global nonlinear analysis collapse with the maximum strength of the pier panels in the hypothesis of infinite strength and stiffness of spandrel strips, that allows predicting the capacity of the building in terms of maximum elastic strength.

These methods have shown to be the most appropriate for design and assessment of masonry buildings, given its access, the simplicity of modelling and easy results interpretation, apart from the fact that their reliability has been demonstrated $[1,9$, $10]$.

Also in Portugal, and in the last years, several protocols [12, 13, 14] were established between research centres, particularly University of Minho, and industry, to develop innovative products to build with structural masonry. The "Alvenaria" software presented here is a result of this effort, and guidelines for its development were based on a benchmarking process, performed at University of Minho, of foreign computer codes for structural design of masonry buildings, particularly with plain (unreinforced) masonry $[9,15]$. As a result from this process, it was concluded that a pushover seismic analysis of the buildings modelled by macro-elements is an adequate approach for the development of a national design and assessment software. 


\section{The "Alvenaria" software}

Development of a design tool for masonry buildings was stated as an important goal to encourage construction with structural masonry in Portugal. The original idea evolves from a spreadsheet to a friendlier environment, where this first version of the "Alvenaria" software is directed to seismic safety verification.

Among the three more prominent methods in the benchmarking process, namely RAN, 3Muri and SAM II, already presented, the first is the one that could be most easily implemented. This is an approach inspired in the POR method that considers an independent "storey mechanism", but RAN allows evolving to a global response analysis of buildings, based on the assumption of a cumulative response of storeys and walls. In the following, the development guidelines of the new software are presented.

\subsection{Assumptions and formulation}

If the original version of the POR method was based on the single hypothesis of diagonal shear failure to walls, post-experience of earthquakes shows that wall panels can also fail by combined shear-flexure (Figure 2a). According to codes $[7,8]$ the sliding shear is another collapse mechanism to consider, even if, in practice, its occurrence is improbable.

Since the Alvenaria calculation engine is inspired in the RAN method, the hypothesis assumed in its development are [11]:

- a typical wall is constituted, in each floor, by pier panels assimilated to onedimensional elements of constant thickness and double curvature restraint conditions, linked to the extremities of floor spandrels that are rigid (axially and with respect to flexure) and infinitely resistant (Figure 2b);

- the horizontal actions of earthquakes are applied at the level of each floor;

- the distribution of horizontal forces between pier panels of each storey, is made proportionally to its stiffness (flexural and shear), taking into account the section reduction by cracking;

- the axial forces applicable to each pier panel are also dependent of the horizontal actions, which are distributed as function of the axial stiffness of panels when considering the spandrels as rigid to flexural (Figure 2c);

- the maximum horizontal load that each storey wall can support derives from the attainment of the elastic limit state of the weakest panel, by combined flexure or shear;

- the material is characterized by an elastic-perfectly plastic constitutive law (Figure 2d);

- the tensile stresses at the end sections of the pier panels are neglected, as their influence is rather small. 


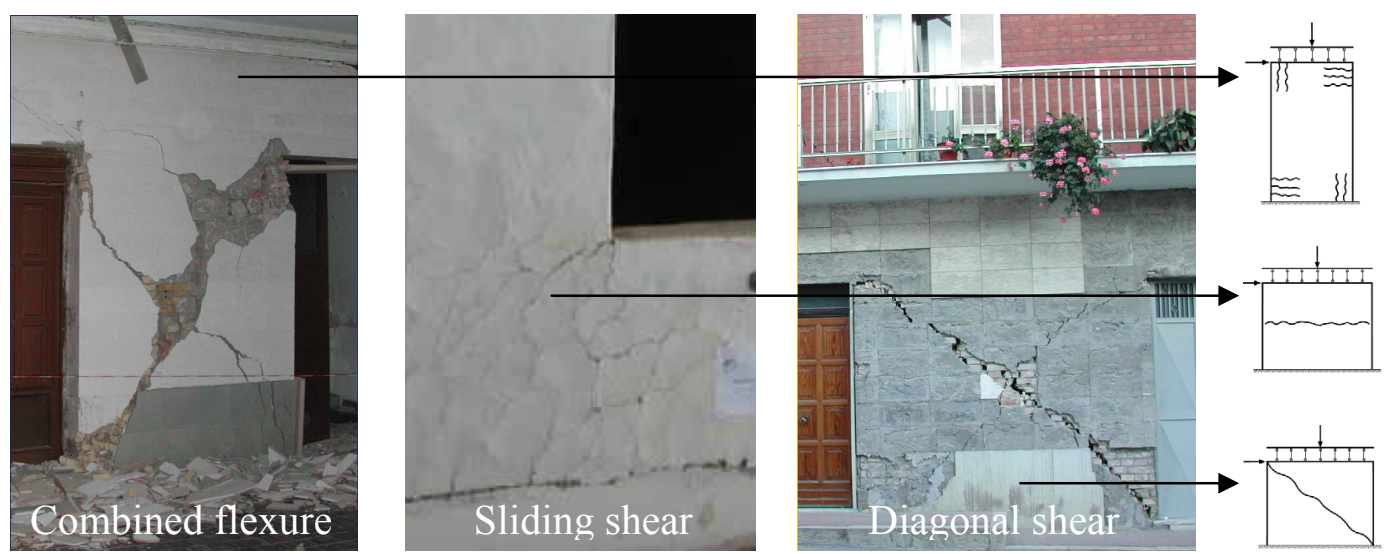

(a)

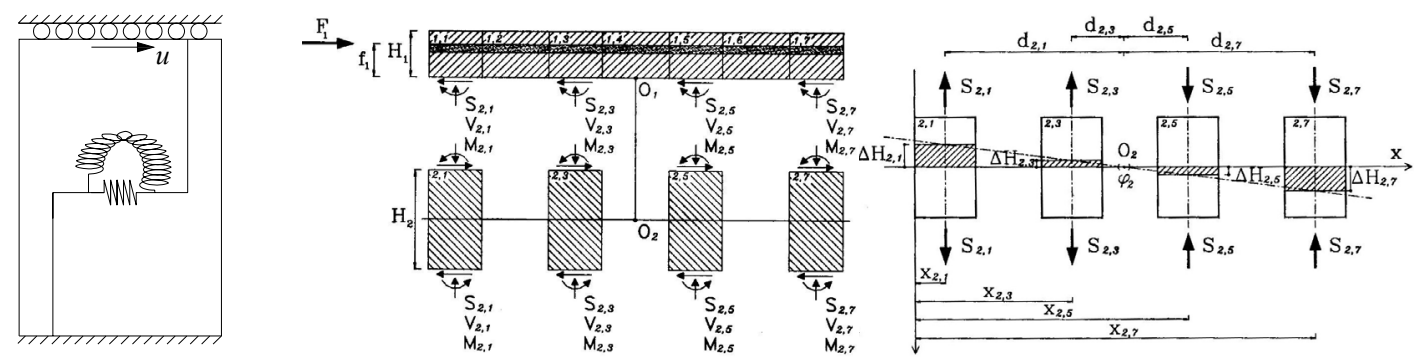

(b)

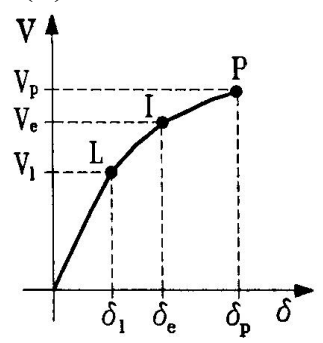

(c)
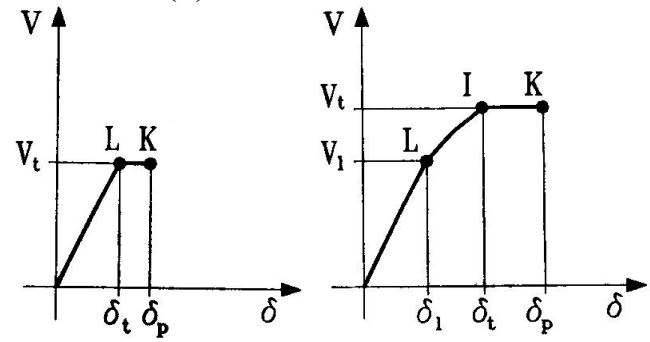

(d)

Figure 2: Illustration of assumptions for the Alvenaria: (a) collapse mechanisms; (b) macro-element; (c) scheme for computation of axial forces by horizontal loads and (d) combined flexure (left) and shear (right) constitutive laws for masonry [11].

The implementation of the Alvenaria calculation engine passes by the following stages, performed for each wall, at each horizontal loading step until the attainment of the elastic limit of the weakest pier panel:

1st: Division of the wall in panels (Figure 3a), and computation of the pier effective height (Figure 3b) as proposed by Augenti [11], in opposition with the Dolce [16] proposal implemented in 3Muri and SAM II computer codes;

2nd: Computation of the axial force on the pier panels under static conditions, $R$, according to the panel zoning schematised in Figure $3 \mathrm{c}-\mathrm{d}$;

3rd: Calculation of triangular distribution of seismic forces in height (Figure 3d);

4th: Computation of axial force variations on piers, $S$, caused by horizontal loads;

5th: Calculation of the effective axial force on the pier panels, $N=R+S$;

6th: Computation of the resistance domains, as presented in Figure 4;

7th: Search of displacements equalization at pier tops, in each storey, by iterations. 


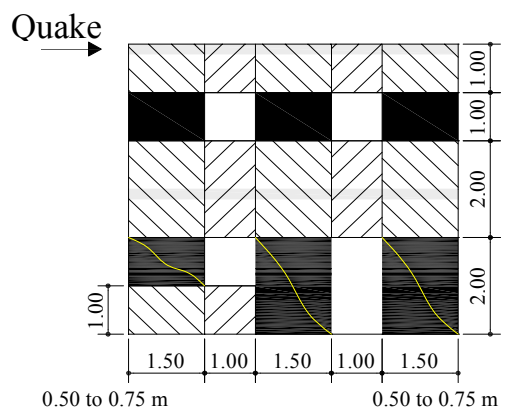

Pier panels $\square$ Spandrel panels

$\checkmark$ Cross panels

(a)
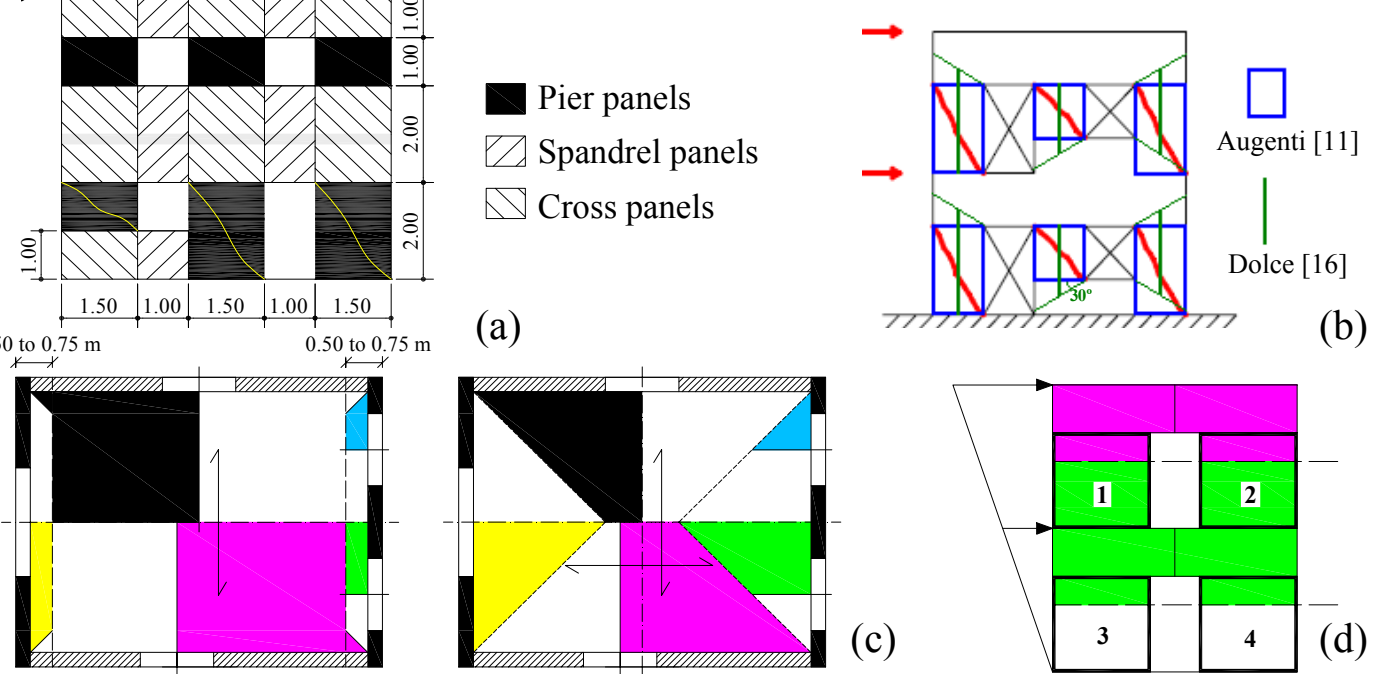

(b)

Figure 3: Calculus considerations for the Alvenaria: (a) panels division; (b) pier effective height; (c) scheme to compute the axial forces on piers from slabs loads; (d) assumed triangular force distribution.

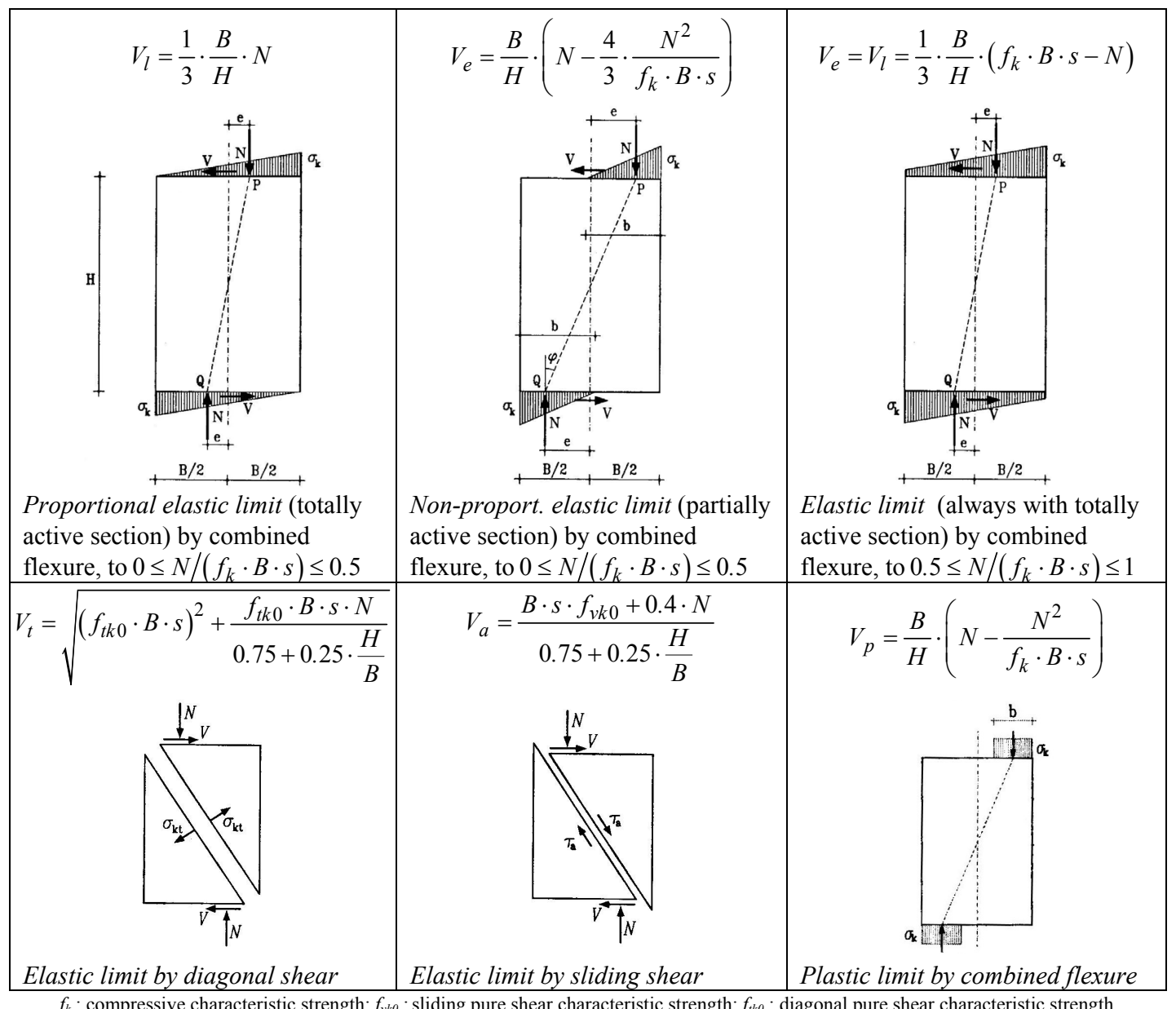

Figure 4: Resistance domains at plane $\bar{V}-\bar{N}$ (adapted from [11]). 
Taking into account the need to ensure the displacements compatibility at the top of the pier panels of each storey wall with rigid spandrels, it is also necessary to predict the displacement at the top of the panels. The characteristic curves of pier panels show branches reflecting different behaviour stages, including elastic proportional, non-proportional elastic and plastic. In this case, only the two first stages are of interest, and the displacement can be computed as a function, assuming the axial force induced by vertical loads as constant, of the shear force $V$ on the panel, through the following expressions [11]:

- Panel in proportional elastic state $\left(0 \leq V \leq V_{l}\right)$

$$
\delta_{l}=\delta_{l V}+\delta_{l M}=\chi \cdot \frac{V \cdot H}{G \cdot A}+\frac{V \cdot H^{3}}{12 \cdot E \cdot I}
$$

where $\chi$ is the shear correction factor, which is generally assumed with a value of 1.2 .

- Panel in non-proportional elastic state $\left(V_{l} \leq V \leq V_{e}\right.$ or $\left.t\right)$

with

$$
\delta_{e}=\delta_{e V}+\delta_{e M}=\chi \cdot \frac{V \cdot H}{G \cdot A} \cdot \zeta_{e V}+\frac{V \cdot H^{3}}{12 \cdot E \cdot I} \cdot \zeta_{e M}
$$

$$
\begin{gathered}
\zeta_{e V}=\frac{1}{3 \eta} \cdot\left[1-2 \cdot \ln \left(\frac{3}{2} \cdot(1-\eta)\right)\right] \text { and } \\
\zeta_{e M}=\frac{1}{(3 \eta)^{3}} \cdot\left[\frac{17 \eta-5}{1-\eta}+12 \cdot \ln \left(\frac{3}{2} \cdot(1-\eta)\right)\right]
\end{gathered}
$$

in which appears the dimensionless parameter reads

$$
\eta=\frac{H}{B} \cdot \frac{V}{N} \text {. }
$$

Then, the elastic displacement of each panel can be predicted, depending on the shear force that is induced. However, to ensure the compatibility (equality) of displacements in the panels of a given storey it is necessary to know the shear force distribution between the panels that leads to the same displacement, which can be obtained through iterative techniques. These techniques aim to find a solution that minimizes (an established objective function.

For the present problem, generalising for a case with $m$ storeys, this function is

$$
\min \left(\sum_{i=1}^{m}\left|\sum_{j=1}^{n} V_{p i s o i, j}-T_{i}\right|+f_{n} \cdot \sum_{i=1}^{m} \sum_{j=1}^{n-1}\left|\delta_{p i s o i, j}-\delta_{p i s o i, j+1}\right|\right)
$$

where:

$V_{\text {pisoi,j }}$ is the horizontal force induced on the panel $j$ of the storey $i$;

$T_{i}$ is shear force on the storey $i$, which accumulates from the upper storeys;

$f_{n}$ is a factor to normalize the displacement conditions in the same magnitude of the force conditions;

$\delta_{\text {pisoi, } j}$ is the displacement at the top of the pier panel $j$ of the storey $i$. 
The proposed method relies on two basic assumptions: the parallel walls deform jointly in correspondence with the rigid diaphragm behaviour of the slabs, neglecting the rotation of the building; and the base shear-displacement "capacity curve" of the building in one direction is calculated as the sum of the capacity curves of walls parallel to this direction. Thus, after computing the curves in elastic regime of the various walls in a given direction, the capacity curve of the building in this direction is the sum of responses provided by each of the walls, within the elastic deformation capacity allowed for the weakest wall.

In short, the Alvenaria method is based on a sequential computation of: the characteristic curves storey-by-storey of each wall; the cumulative capacity curve of each wall from the "sum" of the individual characteristic curves storey-by-storey; and, finally, the building capacity curve in a given direction as the sum of the parallel walls capacity curves. Figure 5 presents the evolution of this calculation.

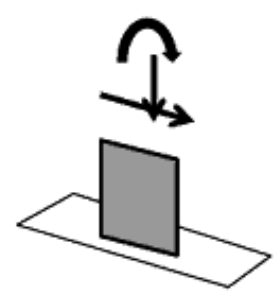

Panel

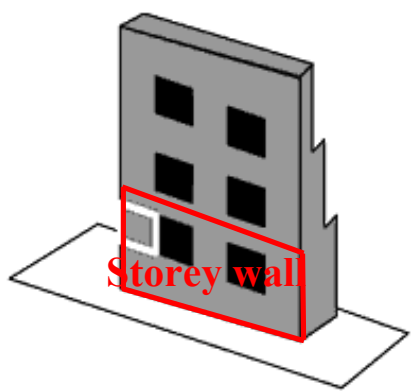

Wall

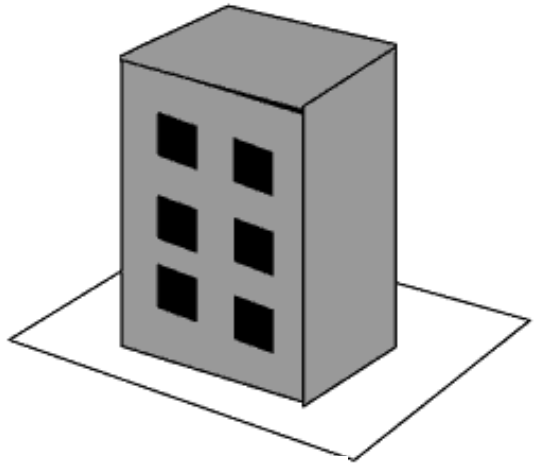

Building

Figure 5: Schematisation of the calculus evolution in the Alvenaria.

\subsection{Safety criterion}

In the Alvenaria software, the safety verification of buildings is based on the confrontation of the seismic base shear solicitation versus the shear capacity of buildings. In other words, the design base shear force of the earthquake action, determined by the lateral force method of analysis defined in EC8 [8], considering zoning, soil type and spectral parameters as defined in the National Annexes of EC8, is confronted with the maximum elastic shear strength on the building capacity curve. The safety rule can be expressed as:

$$
\gamma_{E} \cdot S_{d}(T) \cdot m \cdot \lambda \leq V_{\max }
$$

where:

$\gamma_{E}$ is an amplification factor for the seismic action, which can assume a value of 1.5;

$S_{\mathrm{d}}(T)$ is the design spectrum at fundamental period of vibration of the building, $T$;

$m$ is the total mass of the building;

$\lambda$ is a correction factor, depending on the number of storeys and $T$ value;

$V_{\max }$ is the maximum value of the base shear on the building capacity curve. 


\subsection{Implementation}

The Alvenaria software was implemented in Visual Basic .NET (VB.NET) language, which is an object-oriented computer language that can be viewed as an evolution of Microsoft's Visual Basic (VB) implemented on the Microsoft .NET framework [msdn.microsoft.com/netframework]. This language allows powerful graphical resources, as shown in Figure 6.

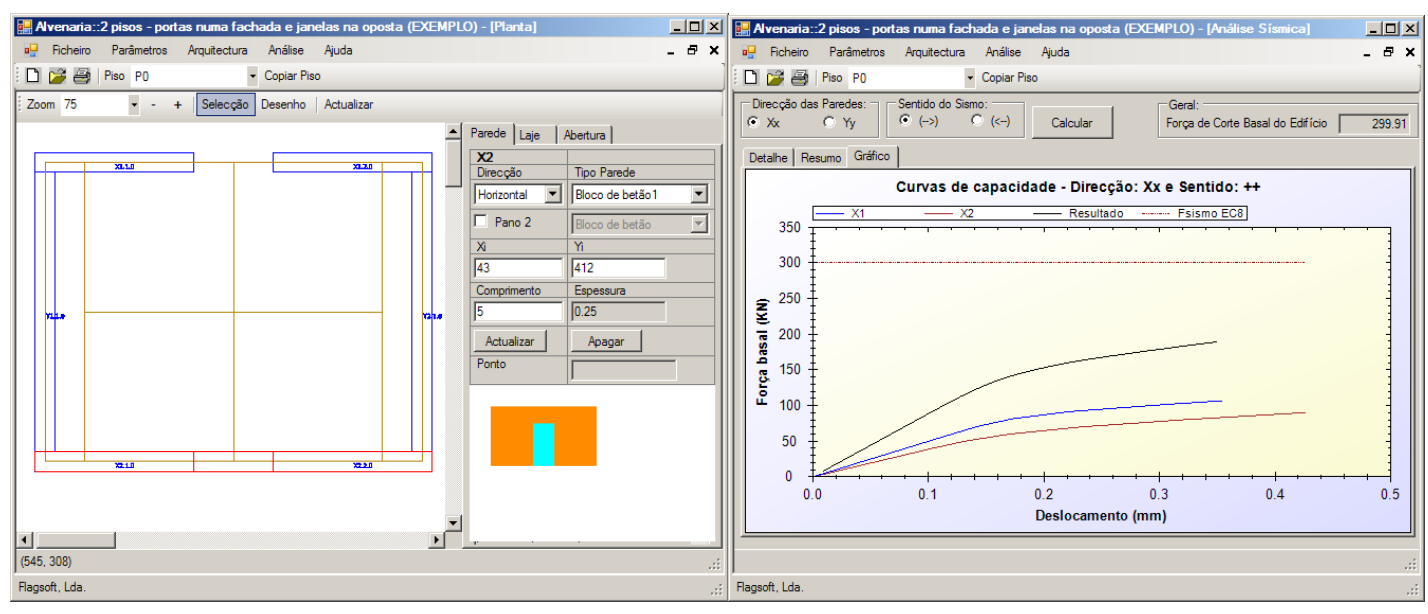

Figure 6: Alvenaria interface: plan definition and computed capacity curve.

\subsection{Case study}

The building studied (Figure 7) presents two storeys with the plan dimensions $5.0 \mathrm{x}$ $4.0 \mathrm{~m}^{2}$ and a height of $3.0 \mathrm{~m}$. Each storey presents two openings in X-direction: a door with $1.0 \times 2.0 \mathrm{~m}^{2}$ and a window with $1.0 \times 1.0 \mathrm{~m}^{2}$. The walls have a thickness of $0.25 \mathrm{~m}$, and a reinforced concrete slab with $20 \mathrm{~cm}$ thickness covers each storey. Slabs are subjected to a dead load of $10 \mathrm{kN} / \mathrm{m}^{2}$. The architectural simplicity of this building has been chosen to capture the essence of the analysis methods.
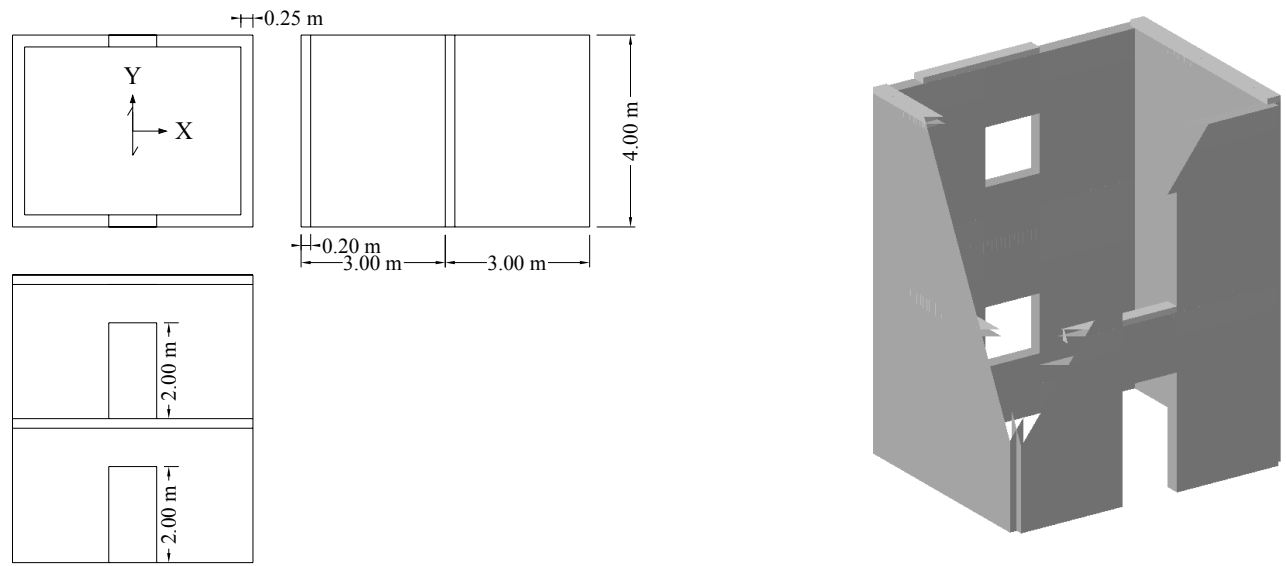

Figure 7: Plan and views of the building. 
The masonry presents the following properties: specific weight $\gamma$ of $20 \mathrm{kN} / \mathrm{m}^{3}$; compressive characteristic strength $f_{k}$ of $5 \mathrm{MPa}$; sliding pure shear characteristic strength $f_{v k 0}$ of $0.15 \mathrm{MPa}$; diagonal pure shear characteristic strength $f_{t k 0}$ of 0.15 $\mathrm{MPa}$; normal elasticity module $E$ of $5 \mathrm{GPa}$; tangential elasticity module $G$ of $2 \mathrm{GPa}$.

Figures 8 and 9 show the capacity curves for walls and building, obtained by different methods, namely Alvenaria/RAN, SAM II and 3Muri. It can be observed that the maximum values of the base shear according to the three methods are very similar. About the global stiffness of the building in the elastic field, the three methods give much different results.

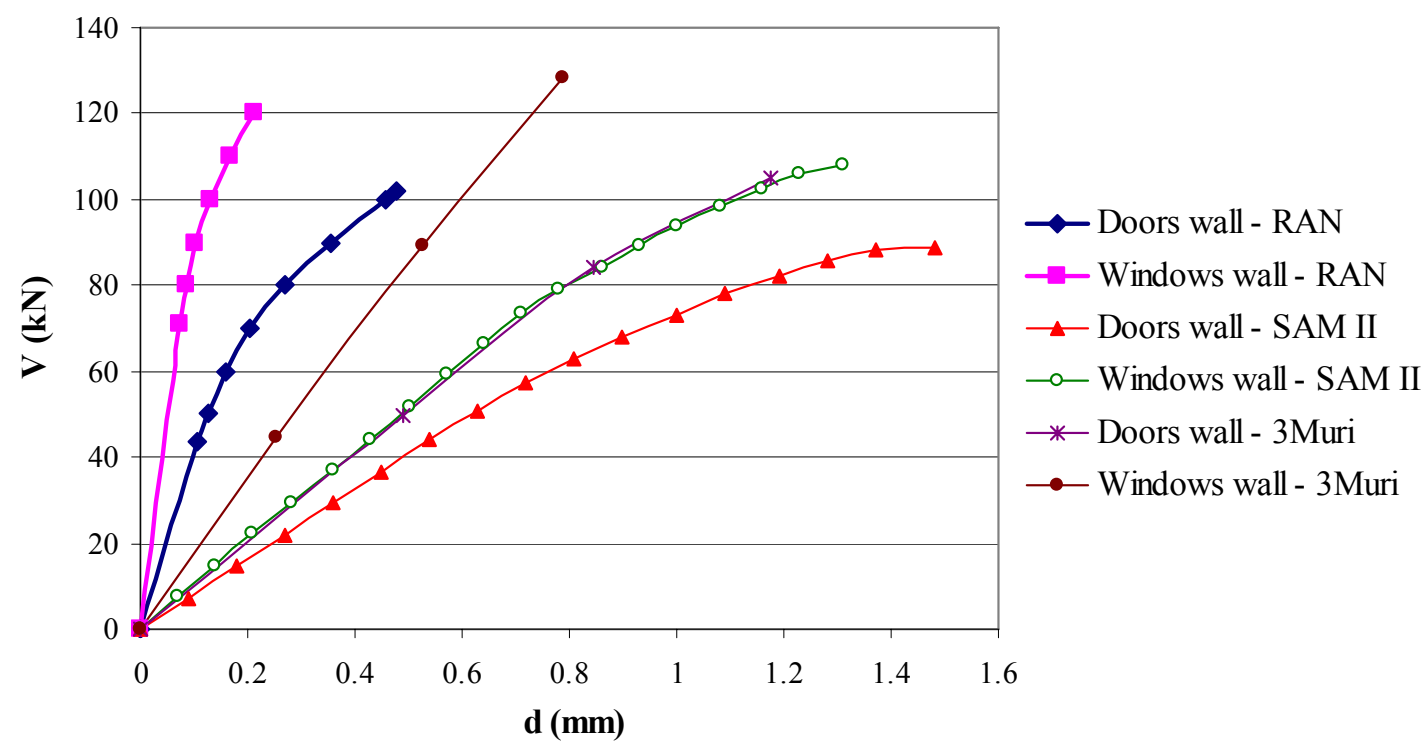

Figure 8: Capacity curves for the open walls, obtained by distinct methods.

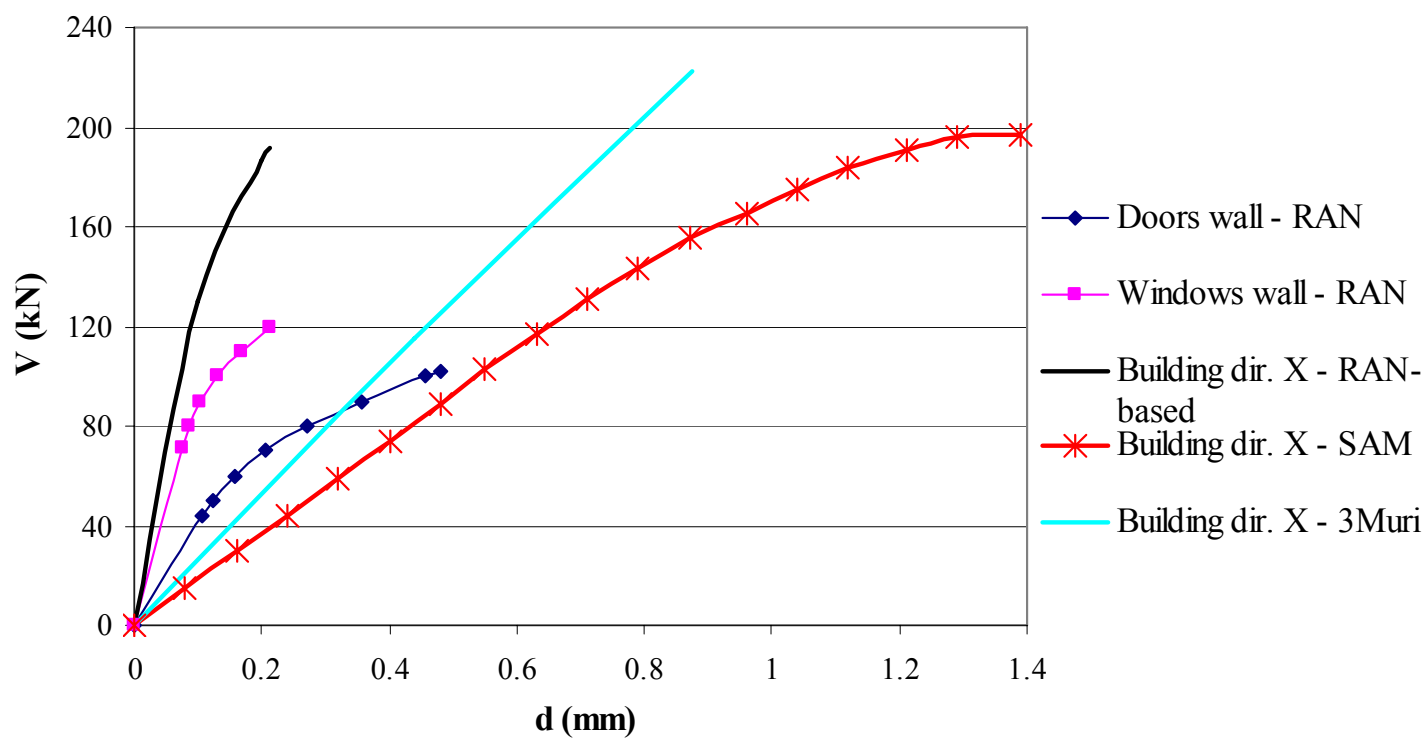

Figure 9: Capacity curves for the open walls and building in X-direction, obtained by distinct methods. 
The successful use of the Alvenaria considers, however, the adoption of an overstrength ratio (OSR) that multiplies the basic behaviour factor $q_{0}$, as proposed by Magenes [17]. If in EC 8 this factor is not permitted for masonry constructions, the Italian code OPCM 3431 propose a value of 1.8 for that ratio in plain masonry buildings of two or more storeys, resulting in a minimum behaviour factor value of $q$ $=1.5 \times 1.8=2.7$. This possibility is explained in reference [18], where a very good correspondence between the non-linear analysis and the linear analysis is obtained by considering a $q$ value in the range $3-4$.

\section{Conclusions}

The developed software is a tool prototype for Portuguese designers, which introduces, in the national context, the concepts of seismic global analysis of buildings in opposition to traditional methodologies based on the analysis by wall elements.

The "Alvenaria" software allows predicting the maximum value of the base shear capacity on the computed capacity curve, which is closed to the obtained by the 3 Muri and SAM II computer codes. Then, the program is ready to be use in forcebased safety verification.

The current version of the Alvenaria should not be seen as a design tool, but as a method of safety assessment. For this reason, its use may also be extended to seismic performance evaluation of existing buildings.

In future, the need to evaluate the effect of rotation of the buildings on the calculation is to be considered. Currently, studies are being made to extend the use of the proposed method to design confined masonry buildings.

\section{Acknowledgements}

The authors acknowledge the support of Project SINALES "Development of an industrialised system for structural masonry", contract IDEIA-70-00130-2004, from Innovation Agency (ADI) in Portugal. The first author also is grateful by the doctoral grant SFRH/BD/41221/2007 from the Portuguese Foundation for Science and Technology (FCT).

\section{References}

[1] R. Marques, P.B. Lourenço, "Potentialities of construction and design of plain masonry buildings", Construção Magazine, submitted January 2009 (in Portuguese).

[2] M. Tomaževič, "The computer program POR", Report ZRMK, 1978 (in Slovene).

[3] P. D'Asdia, A. Viskovic, "Seismic analysis of masonry buildings", Ingegneria Sismica, Anno XI, 1, 32-42, 1994 (in Italian).

[4] F. Braga, D. Liberatore, G. Spera, "A computer program for the seismic analysis of complex masonry buildings", in "Computer methods in structural 
masonry - 4”, G.N. Pande, J. Middleton, B. Kralj, (Editors), E\&FN Spon, London, United Kingdom, 309-316, 1998.

[5] L. Gambarotta, S. Lagomarsino, "On the dynamic response of masonry walls", in "Atti del Convegno Nazionale La Meccanica delle Murature tra Teoria e Progetto", Messina, 1996 (in Italian).

[6] G. Magenes, A. Della Fontana, "Simplified non-linear seismic analysis of masonry buildings", in "Proc. of the British Masonry Society", 8, 190-195, 1998.

[7] OPCM 3431, "General Criteria for Seismic Classification of National Territory and Technical Guidelines for Structures in Seismic Zones", Ordinance of the Minister Council, Rome, May 2005 (In Italian).

[8] EC8, EN 1998-1, "Eurocode 8: Design of structures for earthquake resistance, Part 1: General rules, seismic action and rules for buildings", Brussels, Belgium, December 2004.

[9] R. Marques, P.B. Lourenço, "Benchmarking of commercial software for the seismic assessment of masonry buildings", in "Intern. Seminar on Seismic Risk and Rehabilitation of Stone Masonry Housing", Horta, Portugal, 2008.

[10] N. Augenti, A. Romano, "Seismic design of masonry buildings through macro-elements", in "14th Intern. Brick and Block Masonry Conference", Sydney, Australia, 2008.

[11] N. Augenti, "Il calcolo sismico degli edifici in muratura", ("Seismic design of masonry buildings"), UTET Libreria, 2004 (in Italian).

[12] SINALES, Project "Development of a industrialized system for structural masonry", IDEIA-70-00130-2004, Agência de Inovação, Portugal, 2005-2008.

[13] DISWALL, Project "Development of innovative systems for reinforced masonry walls", COOP-CT-2005-018120, European Commission, 2007-2008.

[14] P.B. Lourenço, G. Vasconcelos, J.P. Gouveia, P. Medeiros, R. Marques, “cBloco: Handbook of structural design", ISBN 978-989-20-1404-3, Cerâmica Vale da Gândara S.A., 2008 (in Portuguese).

[15] I. Maciel, P.B. Lourenço, "Analysis of design programs for masonry structures", Construção Magazine, 21, 19-24, 2007 (in Portuguese).

[16] M. Dolce, "Schematisation and modelling of masonry buildings subjected to seismic actions", L'Industria delle Costruzioni, 242, 44-57, 1991 (in Italian).

[17] G. Magenes, "Masonry building design in seismic areas: Recent experiences and prospects from a European standpoint", in "First European Conference on Earthquake Engineering and Seismology", Geneva, keynote K9, 2006.

[18] P.B. Lourenço, N. Mendes, R. Marques, "Earthquake Design and Assessment of Masonry Structures: Review and Applications", in "The Twelfth International Conference on Civil, Structural and Environmental Engineering Computing", Special Lecture, Funchal, 2009. 